\title{
Mainstreaming of Mobile Assistive Technology: Experts' Thoughts and Opinions
}

\author{
http://dx.doi.org/10.3991/ijim.v6i1.1791 \\ C. Kouroupetroglou, D. Tektonidis, A. Koumpis and I. Ignatiadis \\ ALTEC Software S.A. Thessaloniki, Greece
}

\begin{abstract}
This paper presents the outcomes from the interviews with experts and stakeholders that took part under the study on e-Accessibility2020[1] ("Study on Implications from Future ICT Trends on Assistive Technology and Accessibility", SMART 2010/0077). This study aims to provide the European Commission with recommendations on future research policy, especially regarding Framework Programme 8 (ICT \& FET) and the next Competitiveness \& Innovation Programme (CIP). To achieve that, the study follows a data gathering process from various sources, such as scientific papers, past and running projects deliverables and interviews with experts. The objective of this data gathering process is to identify key trends, micro-trends and weak signals on new technologies that will possibly affect the future of eAccessibility. In this paper we present the findings from a series of interviews with experts and stakeholders which took part during the data gathering process.
\end{abstract}

Index Terms-eAccessibility, mobile accessibility, assistive technology, e-Accessibility standards, Design for all.

\section{INTRODUCTON}

The study on e-Accessibility2020[1] ("Study on Implications from Future ICT Trends on Assistive Technology and Accessibility", SMART 2010/0077) aims to provide the European Commission with recommendations on future research policy, especially regarding Framework Programme 8 (ICT \& FET) and the next Competitiveness \& Innovation Programme (CIP). To achieve that, the study follows a data gathering process from various sources, such as scientific papers, past and running projects deliverables and interviews with experts. The object of this data gathering process is to identify key trends, microtrends and weak signals on new technologies that will possibly affect the future of eAccessibility.

Having identified some of the key and micro trends in the data gathering process the study team developed a preliminary set of scenarios combining various technologies referred during the interviews. The aim of this short paper is to present input we received from our interview sessions with experts.

For the conduct of the interviews we adopted an approach that combines both a specialist and a generalist perspective: Specialist according to the aims of each particular project, and generalist according to "changing user needs, future development of eAccessibility solutions, drivers of change". In the table below we offer some excerpts from each conducted interview -it is well known that this is not a good practice to separate the view from its original setting and set it out of its original context.
In the following sub-sections we cite the - yet not processed findings from discussions - communications interviews that our team has collected and which will be subject to further processing in order to recognize the importance and impact in the different categories, as well as with respect to the adopted ranking scheme for relevance purposes and their possible impact on future research patterns.

\section{INTERVIEWS WITH EXPERTS AND STAKEHOLDERS}

A. On e-accessibility research in general

- Too many accessibility related projects look like mirror images or copycats: instead of promoting a new idea they prefer to take the safe route of enhancing a new trend or - more usually and less risky - build on an existing one. Or they simply combine two new technologies with some 'new' application. Why not ask for a conventional bank loan to finance such a project? The idea of an accessibility research project is that it should open new horizons in the area and not make use of existing and in many cases available for free technologies.

- All research results bear the weaknesses and limitations of the methodologies that have been used for their creation. Technologies change - why should our idea about elderly people's or blind people's needs stay the same? What is the relative value of Braille literacy nowadays for a blind person? Is this going to help him or her get a job? Do we make assumptions about the beneficiaries of our accessibility research work that may probably not hold or not hold at all?

B. On threats of exclusion

- There is need to measure how much exclusion was created due to HCI : how much the gap between accessible ad inaccessible systems and applications has widened in the last ten or twenty years due to the proliferation of new technologies or the introduction of new devices or standards. It seems of peripheral interest but it is quite more important than it seems: we need to measure how much inaccessibility or exclusion our Human Computer Interaction produces. Same way like countries measure their GDP or the poverty rates, we need to know exactly which exclusion or inclusion conditions our HCI produces.

- We evangelise systems that follow Design for All principles but we tend to forget that the industry pays attention only to cost reduction and cost reduction elements when considering new technologies or replacement of old systems with new ones. As long as 
there is no top down demand for systems that offer accessibility, there will be less attention by the industry to promote such solutions. Unless we expect to see the full spectrum of the baby boomers generation to face accessibility problems due to age so that there starts a shift in the way of thinking in the industry.

- We have invested too much hope on visions like Design for All that have not proven their capacity to support wide-level applicability. We should again start thinking small instead of thinking big so that we gain momentum in the accessibility research. Design for All may be a religion or a principle but the world or the industry cannot be governed by such abstractions. It is better to give a boost to the European Assistive Technology industry than burning personyears and scarce money in search of a Holy Grail who nobody saw.

- Lowering the costs of accessible computing should be given priority. If companies that seemed to pioneer the era of accessibility for all now reduce of diversify their efforts from the field, it is high time to look again in the cost-related matters of accessibility. And examine thoroughly who should pay these costs. This may not be a technology problem at all but a political one. However it is the duty of technologists to deliver all the necessary information to the policy makers.

- We need imagination and creativity for planning and conducting research on who could be excluded from using novel user interfaces. If this takes place proactively, we will for sure save costs from adapting inaccessible technologies and solutions.

\section{On internationalisation}

- There is a strong need to internationalize work on eaccessibility. We have for many years researching and working around the very same things and what is now only possible to make a difference and increase the impact of our work is to address it on an international level. International means not only European Union but together with other initiatives from U.S., Canada, Japan, China, Korea and other countries.

- This internationalization would prove beneficial also for the developing countries that mainly lack means to do primary research - in such a context they would be capable to uptake results more easily.

- The Global Public Inclusive Infrastructure [2] may be used as a vehicle that could help the transition to this new era of internationalized research on eaccessibility.

\section{Include all stakeholders}

- $\quad$ Projects are traditionally including one or more user partners that are so to say the recipients of the work carried out in the project. This scheme works only for the project purposes. If you go and see what is the remaining value of many projects, there is no continuity and no real uptake. Why? The reason seems to be the fact that the users have been invited by the end phases of the project preparation and planning on the one hand, while on the other hand they were not asked to contribute with their ideas and needs. Their role was to help in the demonstration of projects that were conceived, designed and specified by the side of researchers, academicians or the industry. So, there is no actual space for the users to speak up and have their voice listened by the other side.

- It is true that the user needs are usually if not $99 \%$ basic and not thrilling or exciting. This means that it is difficult to conceptualise and design a good proposal if you only listen to the user needs. No elderly would ask you to give him an Android phone; no Alzheimer patient carer would ask you to give access to him or her through a social network: their needs are more basic and - if one is allowed to say - more real. In this respect, no Workplan would take care to cover them.

- Exciting projects are not always projects that are dealing with "future things" or "hot technology topics": they may deal with an alternative view or a fresh approach to research issues that have not been successfully covered in the past, or deal with market segments that would not be regarded as justifying commercially funded research. Then there is no reason for having European Union financing research that would have otherwise been carried out by commercial enterprises - the idea is to finance something that will increase the value of our society and the value of how our society performs.

- Training programs for disability representatives to effectively participate in $R \& D$ processes should be given priority. Though there seems to be difficulty in identifying what exactly should they be trained at, it is a process that the research community needs to embrace in order to increase the quality of its research results and outcomes.

- Promote research on how to make accessibility simpler to deliver, apply, configure, support and use and explain to all stakeholders ranging from the designers and the developers, the policy makers, the system vendors, the customers and the users. The idea here is not only to teach but mainly to receive input. Prejudices and stereotypes (see section below) are not always the best way to promote innovation [3].

\section{E. Prejudices and stereotypes}

- It's quite funny that we don't have an accurate idea about how the world at large but also in all its thinsliced appearances treats disabled people: will the technology enabled a blind person to become a car salesperson? Will there be massively open positions for them as e.g. HR Director? Or Financial Directors? Or CEOs? Academic and research communities may accommodate far more easily a disabled person than the industry. There, the gaps are bigger and deeper and we need research about how the new technologies will bring down prejudices and even reverse stereotypes. Same also applies for the case of elderly people: how can we demonstrate that our knowledge society that we have been engineering and generously financing for over ten years now will actually need and make best use of the growing elderly population.

- A blind person is not the same on a universal scale: strolling in the streets of a big metropolis using an advanced navigation system is not necessarily the pressing need of all blind persons. Could - should would: this triptychon needs to be examined each time we think about an accessibility solution. Something would be nice to have but not essential, some- 
thing else could possibly increase accessibility and other indices, however our priorities should be mainly driven by technologies that blind persons should be equipped with in order to support their independent lives and ability to work, communicate and be part of the society at large (community, citizenship) or at small (family, work).

- Research on collaborative accessibility is a must have for the following years. Same way that interoperability is an important issue - you don't want to have isolated islands of functionality, it is the same way that you don't want to have disabled persons being left alone to interact with a more or less accessible system: other people should be capable to interface with them and either assist them in completing a task or simply be able to follow their experience. When we are lost in a portal and ask for assistance, it is important for the human agent to know exactly where we are, which task we were unsuccessfully trying to complete and how to help us best overcome the problem, it is same important to build accessible systems that operate in full transparency for other people. This would be a measure not necessarily for increasing the accessibility but certainly for ensuring the quality of accessibility we offer to the people.

- We need to identify human factors-related barriers to health, education and participation of low income groups. The most tragic situation one can think about is this of a fully accessible (from the interaction point of view) world wide web of services, interactions, experiences and people that will be accessible (from a financial point of view) to 'Haves' and exclude all 'Have-Nots'. Development countries may currently be facing this situation. We have to take immediate lessons and prepare for the extreme that may happen so that this will never happen.

\section{F. Interacting with robots}

- In US there is growing interest (also from the side of the Department of Veterans Affairs) to support research on accessible interaction with robots. For instance, how with the help of a remote human assistant, a person with disabilities may pilot a robotic mobility and manipulation system, and open a refrigerator door to retrieve a pre-prepared meal from home. To this, cooperative control leaves people with disabilities in command, and also grants them the ability to use the capabilities of both the local pilot and a remote human assistant so that they operate safely, effectively and efficiently a robotic system within their natural environment.

- There is need for research into how Assistive Technologies can provide better than typical results (e.g. cyber-human). This way, AT can be given a chance to be regarded not only as a last resort after any accessibility solution or attempt has failed, but also as a field where pioneering research can take place, which may dramatically affect the lives of all disabled included.

\section{G. Learning}

- We need more agility in the way we plan and deliver our projects: from the time that a first glimpse for a new project has happened till the time a project starts many things change - and most importantly: the idea may not be as valid any more. If the framework for planning the work is not enabling for continuous changes, the results of our research will remain suboptimal.

- For the accessibility area we all know that there are some very specific Conferences of high quality like the ACM ASSETS Conference, that reflect the Zeitgeist and the state-of-the-art in the field. So if someone needs to take the pulse of what is going on in accessibility or what will be going on in this area for the next years the best measure is to examine these Conferences. To study the European research projects is not giving any new information as all projects are results of specific calls. So why should one identify a new trend in a set of projects that all responded to a call for tactile interfaces? While in the 'world' of Conferences things are unplanned: researchers and new $\mathrm{PhD}$ students don't follow - fortunately for the time - any central planning idea.

- You can certainly teach people to speak a foreign language. Or a new skill. But how can you teach people on how to acquire all the necessary capacities to become elderly? Learning here has not been addressed - though there is a growing demand.

- We urgently need research on how to increase and widen accessibility in professional education. How can we prepare the several thousands of eaccessibility designers, developers, implementers and trainers? How can our universities catch up with this situation? Is one or two elective courses on accessibility or HCI enough to fill the gap? How much and what exactly should we expect from professional associations like ACM and IEEE internationally or nationally and even locally?

\section{H. Content, content, content}

- Content is the king. Whoever owns the content, or possesses access technologies for the various types or subtypes of content, or can promote the content to its target consumers or plan synergies with platform and device operators, will be finding himself in a favourable position in comparison to all others.

- Imagine who does a blind person depend on? It is the content provider who may unlock and open its content to become fully accessible for the blind person be it the case of a map or a book or a multimedia database. Many previous projects were hiding this aspect by including only demo-purpose content.

- For this situation they were helped greatly as content was governed and administered by other Units of the European Commission than the ones responsible for accessibility.

\section{The superdominance of visual interaction}

- Visual channel is powerful - we all accept this. And nowadays that we have fast internet and the ability to transfer high quality video, support sophisticated graphical interfaces and exploit as much as possible this channel, why not do it? However this is only the one side of the coin.

- The modern individual who is continuously on the move depends, as expected, too much on the visual channel: while walking, in the metro or train, or driv- 
ing on the motorway people send and receive messages, read emails or documents, google or browse on the internet. To do all this, they depend on visual information that is provided by some small(er) or big(ger) visual displays. Why not give a chance to some new form of mainstreaming non visual interaction? Why not have people reading their emails or their newspaper while not reading them? Why not have people editing a document while not having visual access to it? Why not have people googling for information or searching for a restaurant for tonight while not looking at some screen?

- One supporting argument for this is to think about the super rich people who are always accompanied by custody of secretaries and aides who take care of all their stuff. Interaction there goes through them and they usually dictate their wishes or are told about the findings.

\section{J. The interface is not the message}

- We should not only stick to the interface and how to make it accessible - this is only one part of the problem i.e. the interface as it appears to the user. We should focus on the entire interaction dialogue i.e. the logic underneath the interface and how the various 'entities' of the interface relate to 'entities' of the application or the back office system. Like in movies, there is at one level what happens on screen and concurrently there is a plot that is undergoing. We should not so-to-say miss the plot for the show or attraction elements that appear on screen.

- We need research on how to use mobile technologies as a universal middleware in public and private environments. A guess is that it is easier to make a mobile phone with certain technical features interoperable with many applications, systems or services than intervene in the code of all those systems, applications or services and try to make them accessible. This way, the disabled person is empowered to use the mobile phone or device as a powerful and enabling remote controller.

- We need to develop and enforce standardized and harmonized remote HCIs. Not all ATMs follow the same interaction dialogue with their users - and not all ATMs support same or similar interface design patterns. Is this good for the customers? Is this happening on purpose or because of lack of communication amongst bank system designers and operators?

- We need to research the delivery of the same interface to many more varied platforms - one can call it user interface homogeneity or user interface polymorphism - we need to support principles of the design of a system or an application into different platforms. Now there are many objections to this: what happens with platforms that appear later and may support add-ons and features that for previous platforms were unthinkable? And where is the freedom of the developer to adjust and differentiate the interface to new styles or design choices? And in connection to the previous point: why should all modern ATMs operate the same interface as in much older ATMs? Is this free market? These issues are usually discussed during the dinner in many research projects - now we should bring these dinner table discussion items seri- ously as part of the research agendas of future projects.

- There is need to support research on how affective computing can assist accessibility interfaces. Affective computing has been identified as an area that will concentrate the interest of the public, the industry and the research community. However, it has not yet been successfully addressed to which extent this may facilitate accessibility and the related interfaces for various user categories.

- $\quad$ Research on mid- to long-term interaction by disabled and elderly people. People who face chronic disease or disability (and ageing may be regarded as such) need to interact in a way that promotes the development of their needs in such a mid- to long-term horizon. Their needs gradually change and their disease or disability evolves so the prerequisite for any system is to support these changes and be capable to catch up with the evolution. Adaptivity may be an answer to this. Other approaches may relate to affective computing (see above) or reasoning techniques to support this personalization process.

- Promote methodologies to include the human diversity in user interface design. We are all different and need to be treated as such. How harsh or fine-grained can afford to be the modelling of users according to their needs, preferences and capabilities? Human diversity includes also cultural aspects, language and background so it may help us come to a closer personalization degree for our interfaces.

- We need to find out why existing knowledge and standards on accessibility are not known or applied by HCI developers. Which are the reasons or the impediments for this situation and is it related to lack of resources (and if yes, then of which type: monetary, human or technology)?

- How can we reduce the complexity of user interaction while retaining functionality? How can we measure the particular cognitive load that is associated with various user interfaces? There are factors related to the usability and the ergonomic design of our interaction environments which may not be given simple or simplistic answers - they still need more thorough examination and research. Of course, a pending matter is that even if we had answers to these issues how could we widely transfer know-how and knowledge for uptake by the industry?

- Tools and development environments have not attracted researcher's attention en masse. However there is need to research these environments so that they will offer accessibility solutions. In the past, companies would expect to dominate a market by provision of development tools and environments. Nowadays and with the proliferation of the open source and the software-as-a-service movements, nobody truly expects any revenues from investing on tools that would facilitate or even automate accessible design. As mentioned, the need exists and also exists an opportunity for a business success in the area.

\section{K. Accessibility economics}

- In the recent years we talk about software-as-aservice while for several decades now we are all used to the concept of leasing a car or equipment or a 
house. So it seems that it is high time that we make the transition towards new ways to move from purchase to lease or renting accessibility and assistive technology. Why own a communication aid if you can lease one? And why own a navigation system for blind or elderly while renting one as a service? Social insurance agencies may also have their own views on this - it may prove more cost-efficient for them both for the long run and for an immediate introduction; however there is need for exploring market, policy and technology challenges and dynamics. Finally, accessibility matters here again: if you leave the ownership model to move to the leasing or renting, you need intuitive accessibility in the offered solutions as your users don't regard anymore the learning of the system as an asset. As long as you may use a system for a few days or weeks, it needs to be easy-to-use and make the life of the user easy regarding manipulation and maintenance.

\section{CONCLUSIONS}

The association of e-access technology with disabled people has been a barrier to progress. It has even hindered compliance with e-access legislation for online resources. It would therefore be useful to reposition the field in a way that addresses the original concerns, but provides a greater level of motivation and benefit to those who need to act and make changes.

One way forward is to see e-access, not so much as the use of IT to restore functions or capabilities of handicapped people, but to enhance missing, lost or ailing capabilities of all people, enabling them to do things that they normally would not be able to do. This "performance paradigm" has the advantage of considerably expanding the market for e-access devices and services.

Another way forward is to think of e-access as the use of technology to perceive and control the world and the context or environment in which one lives, regardless of whether a person is handicapped or not.

The advantage of this approach is that it enables us to go beyond the basic experience of sight and movement and deal with the full sensory experience of living including the ability to communicate with the emotions and interact with a gesture or a look.

The traditional approach to e-access has put the emphasis on the computer interface and the use of text, but if we think of the human as an input output system, we see that whole areas of human experience have been left out and brining them back into the realm of e-access technologies allows us to make contact with the most exciting and fast changing areas of medicine and brain science. Work on eaccess involving these domains can move on in parallel with traditional efforts, addressing needs of the most needy and anticipating the day when major breakthroughs in advanced prosthetics, exoskeletons, neural engineering, brain modeling and thought controlled machines will be more generally available.

Such a new input-output paradigm is not so much about letters and words but about cognitive and emotional states. New input paradigms could include non-human senses such as sonar, radar, GPS + remote senses transmitted via the internet or the cloud, the direct outputs from other people or even the collective moods of communities such as winning crowds at a football match.

\section{ACKNOWLEDGMENT}

Our thanks to the group of experts working closely with us for the success of our assignment.

\section{REFERENCES}

[1] eAccessibility, http://www.e-accessibility2020.eu/ (accessed on 30/06/2011)

[2] Global Public Inclusive Infrastructure, http://gpii.net/index.html (accessed on 12/07/2011)

[3] T. Kelley, Field Observations with Fresh Eyes, Entrepreneurial Thought Leader Lecture, Stanford University Entrepreneurship Corner, November 12, 2008, http://ecorner.stanford.edu/ authorMaterialInfo.html;jsessionid=D182B88B971D7C56EA DA8AA574D4EC16?mid=2100 (accessed on 04/08/2011)

\section{AUTHORS}

C. Kouroupetroglou holds a PhD in Applied informatics since 2010 from University of Macedonia in Thessaloniki. His PhD research focused on web accessibility, investigating the impact of a semantic web based mechanism in blind users' browsing experience.

Apart from working in research programs funded by various organisations (Greek Ministry of Education, EU, etc.) he is also teaching in the Alexander Technological Institute (ATEI) of Thessaloniki as a scientific associate. (e-mail: chris.kourou@gmail.com).

Dimitris Tektonidis holds a BSc in Software Engineering and a PhD in Computer Science for research in the area of Enterprise Application Integration. His main fields of research are Enterprise Application Integration (EAI), IS interoperability, Service Oriented Architectures (SOA), Web Services, Semantic Web, e-Commerce, eGovernment and Enterprise Systems (ERP, CRM, SCM). (e-mail: dte@altec.gr).

Adamantios Koumpis heads the Research Programmes Division of ALTEC S.A., which he founded at 1996 (then as independent division of Unisoft S.A.). Adamantios holds a $\mathrm{PhD}$ degree from the University of Kingston, UK and a Bachelor degree from the University of Crete, Greece. (email: akou@altec.gr).

Dr Ioannis Ignatiadis has a $\mathrm{PhD}$ in Information Systems from the University of Bath in the UK, as well as undergraduate and MSc degrees in IT and Technology Management.

He has extensive industrial experience as a software consultant in information technology projects for large European multinationals. He also worked as a senior researcher in the implementation of EU Information Society Technologies (IST) projects, notably the LAURA FP5 and the PANDA projects. His research interests evolve around the technical, social and organizational aspects of the development and use of enterprise systems, e-business and service-oriented architecture solutions (email: jignatiadis@googlemail.com).

Work reported here has been funded by the European Commission, DG Information Society and Media, ICT addressing societal challenges, ICT for Inclusion as part of the study on e-Accessibility2020 ("Study on Implications from Future ICT Trends on Assistive Technology and Accessibility", SMART 2010/0077). The study is presented at www.eaccessibility2020.eu. The study is conducted by ALTEC Software Development, Greece in partnership with CKA, Belgium.

Received 15 August 2011. Published as resubmitted by the authors 14 November 2011. 